\title{
COMPETITION INFLUENCE ON PERSONALITY VALUES AND INTERPERSONAL RELATIONS
}

\author{
Irena Gailienė \\ Member of the Editorial Board, Lithuania \\ E-mail: gailiene@splius.tt
}

\section{Dear Readers,}

Market economy initiates competition process development as a driving force and as an outcome. Due to increasing economy development pace, one can predict that in the $21^{\text {st }}$ century these processes are going to be more and more intensive. Competition should be considered in different aspects, because it penetrates not only into production, work, but also into social, interpersonal relations, has an influence on person's maturity. On the one hand, competition conditions encourage the development of personality adaptive abilities, professional, social and personal competence development, lifelong learning and others, however permanent participation in competition hides in itself quite a lot of negative tendencies.

First of all, it would be necessary to accentuate the total value crisis, enclosing various society layers. A lot is being spoken and written about this lately. Two aspects can be discerned in the value crisis manifestation: human being as a unique value is depreciated; universal human terminal values are devaluated. As a matter of fact, such universal human values as justice, freedom, equality of rights, help and respect to others are not forgotten, but very often they are only declared. The real motivation power and force of values reveal when they regulate man's activity and behaviour giving a direction to all this, that is, when a man seeks to realize his values in life.

In the context of competition it is obvious, that a man of its own accord is not a value. He is valued only for how much competitive, strong, rich, successful he is, what his status in society is and so on, without going deeper in what ways everything has been achieved. In other words, competition conditions changed man related value scale so, that moral personality traits and the man himself became valueless. As values are directly related with personality self-evaluation, one source of which is the evaluation by the others, so less competitive, less successful people are going through the sense of worthlessness. The people who feel like this, do not put forward any higher goals, lose any wish for personal improvement. In this way a phenomenon of a snowball rolling from a hill takes an action here. The final result is still increasing social isolation.

Humanistic psychology classics (Rogers, Coulson, 1968) propagated human centered value principle. This means, that every human being, regardless his abilities, prestige in society, material welfare and so on, is unconditionally valued. However, only a mature personality is able to perceive this, constantly trying responsibly, honourably, openly give an answer to his questions: "What is in reality most important in my life? Why is it important? Do I live according to my own values?"

As it is known, competition processes move to social and interpersonal relations, when people compete not only at work but also in personal life. Psychologists humanists very unfavourably valued competition phenomena, discerning a lot of negative aspects in them: open and hidden conflicts, interpersonal relation deterioration or their disintegration, alienation, loneliness and so 
on. Therefore, instead of competition learning to cooperate is offered (Rogers, Stevans, 1968). And, Volume 1, 2012 in reality, team work, cooperation competences are valued more and more. However, what takes place in a formal space, on a social level, very rarely coincides with the action in the psychological space. This means that in a formal, professional intercourse it is possible to learn behave properly, rationally controlling you, but in non-formal, emotional space it is complicated to do this, especially under influence of competition. Because of the fact that emotional links are the basis of interpersonal relations between people and the latter compete for keeping their working place, for higher prestige, for their chiefs' favour and so on, a question arises, is it possible to create these relations and to save them? It would be complicated to give a positive answer to this question, because of dominance of personal interests. Seeking stability in communication, masks are put on in the best case, which show nothing else, but manipulations.

Thus, competition raises great challenges for personality and for society, to overcome which is really necessary. One can find successful communication, good interpersonal relation conditions in humanistic psychotherapy, where three essential requirements are raised for the psychotherapist: authenticity, empathy and unconditional acceptance of the other (Rogers, 1951). It seems that not much is necessary: to audit the scale of values, giving priorities to human values, to be authentic, emphatic, to be able unconditionally accept the others; because they are valuable just only for that they are people, however, it occurs that at present it is very much. 